\title{
FAKTOR-FAKTOR YANG MEMPENGARUHI KEPUASAN MASYARAKAT DALAM PELAYANAN PUBLIK DI DINAS KEPENDUDUKAN DAN CATATAN SIPIL KABUPATEN MAGETAN
}

\author{
Oleh: Zaini Rohmad ${ }^{1}$
}

\begin{abstract}
ABSTRAK
Penelitian ini bertujuan untuk mendeskripsikan faktor-faktor yang memepengaruhi dari kepuasan stakeholder terhadap pelayanan dan kinerja Kantor Dinas Kependudukan dan Catatan Sipil Kabupaten Magetan.

Penelitian ini menggunakan pendekatan survei yang dilakukan terhadap stakeholder di Kantor Dinas Kependudukan dan Catatan Sipil. Partisapan survei diberikan kuesioner yang berisi pernyataan-pernyataan yang digunakan untuk mengukur kepuasan, koordinasi, perencanaan, kepemimpinan, dan pengawasan yang dilakukan oleh Kantor Dinas Kependudukan dan Catatan Sipil. Teknik sampel dengan purposive sampling dengan teknik insidental. Responden dalam penelitian ini adalah sebanyak 200 responden dengan missing 7 responden yang berasal dari warga masyarakat yang menggunakan pelayanan yang diberikan Dinas Kependudukan dan Catatan Sipil Kabupaten Magetan. Teknik Analisis dengan product moment dan dilanjutkan dengan analisis regresi ganda.

Hasil menunjukan bahwa adanya korelasi yang tinggi antar variabel. Dengan analisis bevariat menunjukkan bahwa keempat variabel independen berhubungan positif signifikan dengan tingkat kepuasan masyarakat. Dengan analisis regresi ganda, tingkat kepuasan masyarakat dipengaruhi oleh 2 variabel independen, yaitu perencanaan dan pengawasan. Perencanaan berpengaruh positif terhadap kepuasan stakeholder (pelayanan publik) secara signifikan dan pengawasan berpengaruh negatif terhadap kepuasan stakeholder secara signifikan. Analisis bevariat variabel independen atau variabel prediktor berpengaruh secara signifikan terhadap kepuasan masyarakatsebagai variabel kriterium. Dengan demikian, kepuasan publik masyarakat Kabupaten Magetan dipengaruhi oleh variabel perencanaan, koordinasi, pengawasan dan kepemimpinan. Namun variabel yang berpengaruh positif secara signinikan terhadap pelayanan publik masyarakat Kabupaten Magetan dipengaruhi oleh variabel perencanaan, pengawasan dan kepemimpinan transaksional, sedang koordinasi kurang tampak pengaruhnya.

Implikasi dari penelitian ini memberikan implikasi terhadap teori dan praktik tatakelola kantor Dinas Kependudukan dan Catatan Sipil. Hasil dari penelitian ini sejalan dengan teori stakeholder, yaitu terdapatnya hubungan dan pengaruh yang erat antara perencanaan yang baik, pengawasan yang teliti dan kepemimpinan yang mumpuni terhadap tingkat kepuasan yang dirasakan oleh para stakeholder (pemangku kepentingan).
\end{abstract}

Keyword : Disdukcapil, Kepuasan Publik, dan faktor-faktor yang mempengaruhinya.

\footnotetext{
${ }^{1}$ Staff Pengajar Program Studi Pendidikan Sosiologi-Antropologi, Fakultas Keguruan dan Ilmu Pendidikan, Universitas Sebelas Maret Surakarta
} 
Abstract

This study aims to describe the factors that influence the satisfaction of stakeholders to the service and performance of the Office of Population and Civil Registry of Magetan Regency. This study uses a survey approach conducted on stakeholders in the Office of Population and Civil Registry. Participatory surveys were given a questionnaire containing statements used to measure satisfaction, coordination, planning, leadership, and supervision carried out by the Office of Population and Civil Registry. Sample technique with purposive sampling with incidental technique. Respondents in this study were as many as 200 respondents with missing 7 respondents who came from citizens who use services provided by the Department of Population and Civil Registry of Magetan Regency. Analysis technique with product moment and continued with multiple regression analysis.

The results show that there is a high correlation between variables. The bevariate analysis showed that the four independent variables were positively correlated with the level of community satisfaction. With multiple regression analysis, the level of community satisfaction is influenced by two independent variables, namely planning and supervision. Planning has a positive effect on stakeholder satisfaction (public service) significantly and supervision negatively affects stakeholders' satisfaction significantly. Bevariate analysis of independent variables or predictor variables significantly influence public satisfaction as a criterion variable. Thus, the public satisfaction of Magetan Regency is influenced by the variables of planning, coordination, supervision and leadership. However, the variables that positively influence the public service of Magetan Regency are influenced by the variables of planning, supervision and transactional leadership, while the coordination is less visible.

The implications of this study provide implications for the theories and practices of the Office of Population and Civil Registry office. The results of this study are in line with the stakeholder theory, namely the presence of close relationships and the close influence between good planning, careful supervision and leadership qualified to the level of satisfaction felt by stakeholders (stakeholders).

Keyword: Disdukcapil, Public Satisfaction, and the factors that influence it 


\section{PENDAHULUAN}

Pelayanan publik merupakan bagian integral dari mekanisme sistem pemerintahan di samping fungsi. Malalah pokok yang menjadi perhatian kita adalah bahwa suatu pelayanan itu terdiri yang terdiri dari penyelenggaraan dan penerimaan layanan (Costumer). Makin luasnya lingkup pelayanan dan jasa-jasa publik (public service) yang dikelola pemerintah meliputi segenap aspek kehidupan masyarakat, hendaknya diikuti oleh kualitas pelayanan yang baik. Ketika berbicara pelayanan, sebenarnya masyarakat sudah memerlukan pelayanan publik ketika seseorang berada dalam kandungan ketika hendak diperiksa oleh dokter pemerintah, setelah lahir mengurus akta kelahiran, saat mencapai usia 17 tahun memerlukan identitas dan (KTP), menjalani pendidikan, mendapatkan macam-macam perijinan dan sebagainya sampai seseorang meninggal dunia membutuhkan surat pengantar untuk penguburan ataupun surat kematian/akte kematian (Zaini Rohmad.dkk. 2014; 2015)

Dalam menjalankan tugasnya keberadaan birokrasi pemerintahan menjadi suatu yang tidak bisa ditawar-tawar lagi dan mereka akan selalu menentukan aktifitas mereka (Kumorotomo dan Margono, 1994). Pelayanan Publik adalah segala kegiatan yang dilaksanakan oleh penyelenggara pelayanan publik sebagai upaya pemenuhan kebutuhan publik dan pelaksanaan ketentuan perundang-undangan, dimana dalam penyelenggaraannya, aparatur pemerintah bertanggung jawab untuk memberikan pelayanan yang terbaik kepada masyarakat dalam rangka menciptakan kesejahteraan masyarakat. Masyarakat berhak untuk mendapatkan pelayanan yang terbaik dari pemerintah karena masyarakat telah memberikan dananya dalam bentuk pembayaran pajak, retribusi dan berbagai pungutan lainnya Mahmudi (2005). Pendapat tersebut mengisyaratkan betapa besarnya peran dan fungsi pemerintah dalam pemenuhan kebutuhan masyarakat, sebagai perwujudannya pemerintah wajib memberikan pelayanan terbaik kepada masyarakat (public Service) dengan orientasi dan penekanan kepada mendahulukan kepentingan publik, mempermudah proses, mempersingkat prosedur dan biaya yang ringan (Zaini Rohmad, dkk., 2015).

Dalam era reformasi dan otonomi pelayanan yang diberikan oleh satu organisasi pemerintah akan menjadi tolak ukur atau indikator bagi publik menilai kinerja suatu organisasi pemerintah, sehingga akan memperbesar tanggung jawabnya dalam pemenuhan kebutuhan publik --yang makin lama makin meningkat 
kebutuhannya. Pelayanan yang terbaik yang diberikan kepada publik akan menumbuhkan kepercayaan atau dukungan publik kepada pemerintah atau organisasi pelayan. Berdasarkan dari berbagai fungsi tersebut, maka pemerintah harus semakin pandai memilah dan memilih urusan yang masih dikelolanya secara langsung. Mengingat ada beberapa fungsi yang pelaksanaannya dapat diserahkan kepada pihak swasta dengan menggunakan pola kemitraan (partnership) antara pemerintah dan swasta untuk menyelanggarakannya. Namun dalam kaitannya dengan sifat barang privat dan barang publik murni, maka tidak ada pilihan lain kecuali pemerintah yang berkewajiban menyediakan barang publik tersebut, khususnya yang berkaitan dengan rules atau aturan yang berlaku (kebijakan publik).

Karakteristik manajemen sektor publik sangatlah berbeda dengan manajemen sektor swasta. Perbedaan karakteriktik tersebut adalah tujuan utamanya melayani masyarakat. Pada sektor swasta mendasarkan pada pilihan individu dalam menentukan pasar, sehingga pelayanan sektor swasta dituntut untuk dapat memenuhi selera dan pilihan individu untuk memenuhi kepuasan pelanggan. Oleh karena itu produk yang dihasilkan disesuaikan dengan pasar sasaran yang dituju, tidak memproduksi masal untuk semua pelanggan. Produk yang di hasilkan lebih bervariatif dan fleksibel untuk memenuhi permintaan pelanggan yang bervariatif. Disamping hal tersebut dengan sektor publik, dalam memberikan pelayanan tidak mendasarkan pada pilihan individu akan tetapi mendasarkan pada pilihan kolektif. Sektor publik mendasarkan pada tuntutan masyarakat yang sifatnya kolektif. Pilihan kolektif masyarakat biasanya disampaikan melalui perwakilan dalam hal ini Dewan Perwakilan Rakyat baik di tingkat Pusat maupun Daerah.

Banyak faktor yang mempengaruhi tingkat kepuasan masyarakat pengguna layanan publik. Dalam penelitian ini mencoba mengindentifikasi faktor-faktor yang mempengaruhi kepuasan masyarakat. Dalam penelian ini menggunan empat faktor yaitu 1) Perencanaan, 2) Koordinasi, 3) Pengawasan, 4) Kepemimpinan.

\section{TELAAH LITERATUR}

Menurut teori stakeholder, Freeman (1984) mendefinisikan stakeholder sebagai kelompok atau individu yang dipengaruhi oleh atau dapat mempengaruhi pencapaian tujuan organisasi. Pada awalnya konsep stakeholder menyebutkan bahwa 
tanpa dukungan dari stakeholder dalam organisasi keberadaan organisasi tersebut akan sia-sia (Zsolnai, 2006). Lebih dalam lagi Gray, Dey, Owen, Evans, Zadek (1997) menyebutkan bahwa stakeholder adalah "someone with a right to account".

Prinsip teori stakeholder menurut Robson, Robson (1996) bahwa organisasi diberikan kepercayaan untuk beroperasi didasarkan atas kontrak sosial dengan pihak stakeholder. Salah satu strategi untuk menjaga hubungan atau kontrak sosial antar para stakeholder adalah dengan memperhatikan kepentingan stakeholder. Dalam sektor swasta stakeholder diterjemahkan menjadi beberapa pihak yaitu konsumen, pemilik modal, suplier, pemerintah, pesaing, media, karyawan, orgainasi komunitas lokal, dan public group (Roberts, 1992).

Dalam menjalankan kegiatan pelayanannya Dinas Kependudukan dan Catatan Sipil Pemerintah Kabupaten Magetan melibatkan beberapa stakeholder. Stakeholder tersebut terlibat didalam pelayanan yang dilakukan oleh Dinas Kependudukan dan Catatan Sipil. Stakeholder inti yang terlibat dalam kegiatan pelayanan tersebut adalah warga masyarakat yang membutuhkan pelayanan misalnya pembuatan akta kelahiran, surat kematian, surat kepindahan, pembuatan KTP, KK, dan lain sebagainya.

Stakeholder theory dianggap mampu menyelesaikan dan menguraikan konflik karena dalam praktiknya, setiap pelayanan yang dilakukan oleh Dinas Kependudukan dan Catatan Sipil Pemerintah Kabupaten Magetan selalu melibatkan stakeholder yang dalam hal ini diterjemahkan menjadi warga masyarakat.

\section{Good Governance dalam NPM (New Public Management)}

Good Governance menjadi faktor utama dalam suatu organisasi agar dapat tercapai goal congruence antar faktor yang mempengaruhinya. Governance merupakan tantangan bagi setiap pelayan publik untuk meningkatkan capacity building guna kepentingan masyarakat yang lebih luas (Bucknall, Damania, Rao, 2006). Ruang lingkup dari governance atau tata kelola harus dimengerti dan adaptif oleh semua anggota organisasi sehingga mampu menjawab permasalahan yang ada dilapangan (Allan, Xia, Pahl-Wostl, 2013). Adanya pemahaman stakeholder terhadap good governance suatu organisasi mampu meningkatkan peran koordinasi sehingga mampu membangun perekonomian sekitar didasarkan atas destinasi pariwisata yang berkelanjutan. Pernyataan tersebut sesuai dengan penelitian Song, Liu, Chen (2012) 
bahwa good governance pada internal organisasi yang efektif dalam rantai nilai pariwisata ditandai dengan adanya keuntungan bagi pengembangan destinasi wisata yang berkelanjutan. Seiring berjalannya waktu dan kondisi geografis, peran governance dalam organisasi berubah disesuaikan dengan tujuan tertentu untuk membuat kemajuan dalam pengamanan ekonomi, sosio-curtural, dan tujuan pembangunan lingkungan yang berkelanjutan (Bramwell, 2011).

Berkaitan dengan konsep New Publik Management (NPM) ada lima dimensi dari kualitas pelayanan. (1) tangible (bukti fisik) sesuatu yang kasat mata seperti pakaian, fasilitas fisik, termasuk senyum dan sikap ramah. (2) reliability (keandalan) yaitu kemampuan memberikan pelayanan yang di janjikan dengan segera, akurat, dan memuaskan. Contohnya kalau masyarakat di minta menunggu satu jam, maka kurang dari satu jam harus sudah selesai. (3) responsiveness (daya tanggap) yaitu memberikan respon yang tepat dan segera. Respon ini harus konsisten dari waktu ke waktu. (4) assurance (jaminan) yaitu kepastian yang menjamin kepada masyarakat mencakup kemampuan, pengetahuan, dapat di percaya dan bebas dari keragu-raguan. (5) empaty meliputi kemudahan dalam melakukan hubungan komunikasi yang baik, perhatian pribadi dan memahami kebutuhan masyarakat (Mahmudi, 2005) dan (Fandy, 1997, 2000).

\section{Pengembangan Hipotesis}

Perencanaan strategi merupakan sebuah usaha yang dilakukan untuk menghasilkan aksi dan keputusan fundamental yang tepat sehingga dapat menunjukkan apa yang organisasi harus lakukan dan mengapa melakukan hal tersebut (Bryson, 2011). Berry, Wechsler (1995) mendefinisikan perencanaan strategis sebagai proses sistematis untuk mengendalikan dan mengarahkan organisasi dalam kaitannya dengan lingkungan serta permintaan dari stakeholder eksternal, mulai dari formulasi strategi hingga implementasi strategi. Perencanaan yang matang akan memudahkan langkah manajemen dalam menentukan arah organisasi sehingga kepuasan kerja dan kepuasan pelanggan dapat tercapai. Sesuai dengan perspektif teori stakeholder, dan atau pemenuhan kebutuhan stakeholders merupakan elemen penting dalam perencanaan di semua bidang (Sautter dan Leisen, 1999). Stakeholder yang telah 
terpenuhi kebutuhannya dalam hal ini adalah pelayanannya secara otomatis akan mendapatkan tingkat kepuasan yang tinggi dari sebuah organisasi.

Penelitian terdahulu yang pernah dilakukan oleh (Kim, 2002) menemukan adanya hubungan positif signifikan antara perencanaan strategis partisipatif dengan tingginya tingkat kepuasan kerja. Penelitian Berry dan Wechsler (1995) juga mengindikasikan bahwa terdapat hubungan antara perencanaan yang baik dengan kepuasan kerja yang terdapat pada instansi publik. Penelitian yang mencoba menemukan hubungan antara perencanaan strategis dengan tingkatkepuasan masih cukup minim. Oleh karena itu, penelitian ini berusaha mengungkap pengaruh perencanaan terhadap kepuasan kerja dan kepuasan pengguna layanan publik. Dengan demikian, hipotesis pertama berbunyi: (H1): Perencanaan Berpengaruh Positif terhadap Tingkat Kepuasan dan Pelayanan yang Diberikan oleh Dinas Kependudukan dan Pencatatan Sipil (Dipendukcapil).

Koordinasi menjadi bagian penting dari pelaksanaan manajemen dalam suatu organisasi. Pengembangan pelayanan publik menjadi penting disaat adanya keinginan oleh pihak Pemerintah Daerah dan pemerintah pusat untuk mengembangkan pelayanan tersebut. Penelitian Song, Liu, Chen (2012) menjelaskan bahwa kunci sukses dalam pengembangan tersebut adalah memastikan bahwa koordinasi antar stakeholder berjalan dengan efisien, kooperatif, dan terintegerasi. Peran para stakeholder sangat berpengaruh terhadap kepuasan pengembangan pelayanan. Hal tersebut menyatakan bahwa fungsi stakeholder dikoordinasikan untuk menghasilkan peran aktif atau partisipasi yang optimal mengenai kebijakan tertentu yang akan dilaksanakan. Perlunya koordinasi yang baik antar para stakeholder adalah adanya koordinasi atau perencanaan yang baik dalam penyelenggaraan pelayanan publik. Berdasarkan uraian di atas dapat diduga bahwa koordinasi antar unit atau organisasi dapat berpengaruh terhadap tingkat kepuasan dan pelayanan di masyarakat. Berdasarkan uraian di atas, maka hipotesis kedua dapat dirumuskan sebagai berikut :

(H2): Koordinasi Berpengaruh Positif terhadap Tingkat Kepuasan dan Pelayanan yang Diberikan oleh Dinas Kependudukan dan Pencatatan Sipil (Dipendukcapil).

Pengawasan sudah banyak dikaji dalam ilmu-ilmu organisasi dengan temuantemuan yang dapat diteliti. Selama proses pengawasan berlaku mekanisme 
pengawasan, dan berlaku mekanisme memastikan sesorang karyawan atau bawahan melakukan pekerjaan dengan benar dan selesai dengan tepat (Nasir dan Masek, 2015). Dengan demikian antara atasan dan bawahan perlu tahu tanggung jawab mereka dalam bekerja secara efektif.

Penelitian dari (Frieder, Hochwarter, DeOrtentiis, 2015) menyebutkan bahwa pengawasan dengan cara yang kasar adalah salah, pengawasan dengan cara yang kasar memiliki efek yang merugikan pekerja dan berdampak negatif pada rendahnya kepuasan kerja, niat untuk mendapatkan omzet yang tinggi, dan kelelahan emosional psikologis membuat pekerja tidak nyaman. Pengawasan dianggap kasar apabila pengawas terlibat permusuhan baik verbal maupun non-verbal terhadap bawahan mereka (Lyu, Zhu, Zhong, Hu, 2016). Dalam pengawasan terdapat sisi gelap, misalnya dalam menilai sebuah pekerjaan seorang atasan menilainya secara subjektif. Penilaian secara subjektif seharusnya tidak diperbolehkan dalam sebuah pengawasan. Menurut Harvey, Harris, Gillis, Martinko (2014) seseorang akan merasakan bahwa dia telah mangalami pengawasan secara kasar atau tidak.

Menurut Nishimura, Suzuki (2016) menyebutkan bahwa aspirasi intrinsik untuk membuat uang yang cukup untuk para karyawan dalam tenaga kerja dibandingkan dengan negara kaya atau maju. Bawahwan berhadap diperhatikan dalam hal kepuasan dalam hidup oleh atasannya. Dalam bidang tertentu diperlukan berpengawasan agar kinerja bawahan dapat terkontrol (Hatipoglu, Alvarez, Ertuna, 2016). Pengawasan itu sendiri sangat diperlukan dalam lingkunagan kerja karena karyawan atau bahwan yang berhubungan dengan kondisi psikologis (Frieder, Hochwarter, DeOrtentiis, 2015). Berdasarkan uraian diatas dapat diduga bahwa tingkat kepuasan masyarakat dipengaruhi oleh pengawasan dan pelayanan yang optimal. Dengan demikian, hipotesis yang ketiga dapat dirumuskan sebagai berikut :

(H3): Pengawasan Berpengaruh Positif terhadap Tingkat Kepuasan dan Pelayanan yang Diberikan oleh Dinas Kependudukan dan Pencatatan Sipil (Dipendukcapil).

Valente, Dredge, Lohmann (2015) mengungkapkan bahwa menyatakan bahwa power-sharing dan kolaborasi dapat mendukung penerapan strategi yang efektif dalam bebagai bidang. Dua hal tersebut berhubungan erat dengan tipe kepemimpinan yang diterapkan dalam sebuah organisasi. Ugboro, Obeng (2000) 
menemukan bahwa terdapat korelasi positif antara kepemimpinan, employee empowerment, kepuasan kerja, dan kepuasan pelanggan. Hasil tersebut menunjukkan bahwa komitmen pemimpin untuk meningkatkan kinerja memiliki efek yang positif terhadap pengembangan kinerja bawahannya. Selain itu, komitmen dari pemimpin juga dapat meningkatkan kepuasan dari staff ataupun pelanggan. Hasil yang sama juga ditemukan oleh Fuller, Morrison, Jones, Bridger, Brown (1999) yang menemukan bahwa psychological empowerment memoderasi hubungan antara transformational leadership pada kepuasan kerja. Berdasarkan uraian diantas dapat diduga bahwa kepemimpinan transaksional berpengaruh gerhadap tingkat pelyanan dan tigakt kepuasan masyarakat. Dengan demikian, hipotesis ke empat adalah: (H4): Kepemimpinan Berpengaruh Positif terhadap Tingkat Kepuasan dan Pelayanan yang Diberikan oleh Dinas Kependudukan dan Pencatatan Sipil (Dipendukcapil).

\section{METODE PENELITIAN}

Penelitian mengunakan pendekatan deskriptif korelasional. Deskriptif dapat dibedakan menjadi dua, yakni: (1) descriptive survey status dan (2) descriptive survey eksplorative. Jenis penelitian petama hanya menggambarkan keadaan apa adanya, tanpa melihat sebab akibat terjadnya keadaan tersebut. Sedangkan jenis penelitian kedua di samping melihat apa adanya, juga melihat faktor-faktor apa saja yang mempengaruhi kejadian tersebut. Bedasarkan uraian di atas, penelitian ini tidak mengadakan perlakuan, tetapi melihat faktor-faktor yang mempengaruhi tingkat kepuasan yang diterima oleh masyarakat.

Penelitian ini menggunakan data primer yang diperoleh secara langsung dari masyarakat, dengan metode survey lapangan menggunakan alat pengukur kuesioner-yang telah disiapkan dengan validitas construct dan content dan reliabitas alpha. Kuesioner yang disebar mencakup poin poin yang menjelaskan tentang perencanaan, koordinasi, pengawasan dan kepemimpinan serta tingkat kepuasan stakeholder yang terdiri warga masyarakat yang memerlukan pelayanan Dinas Kependudukan dan Catatan Sipil. Penelitian ini merupakan penelitian kuantitatif dengan total sampel sebanyak 200 dengan missing 7 responden, dan data berjalan sebesar 193 responden. 
Teknik analisis yang digunakan dalam penelitian ini dengan product moment untuk mengetahui hubungan reprosical dan analisis regresi berganda karena terdiri dari satu variabel dependen dengan beberapa variabel independen (Sekaran dan Bougie, 2010).Variabel adalah sesuatu yang dapat memiliki nilai-nilai yang bervariasi, nilai tersebut dapat dibedakan pada waktu yang sama untuk objek atau orang yang sama, atau pada waktu yang sama untuk objek atau orang yang berbeda (Sekaran dan Bougie, 2010). Model dalam penelitian ini adalah sebagai berikut:

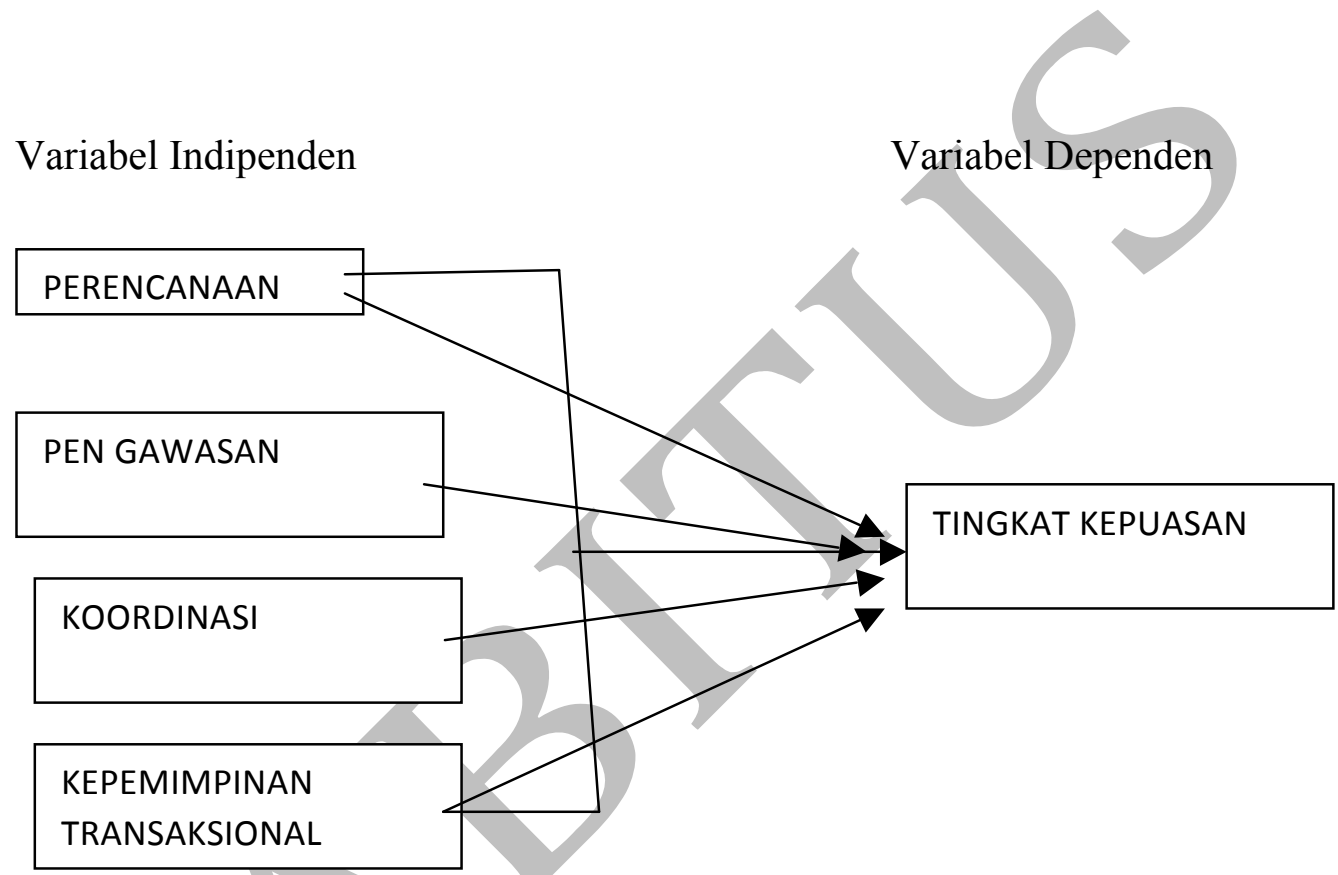

Variabel Perencanaan, Koordinasi, Pengawasan dan Kepemimpinan sebagai variabel bebas dan tingkat kepuasan merupakan variabel kriterium. Instrumen yang digunakan dengan kuesioner yang menggunakan skala Rensist likert yang telah dimudikasi dengan skor 1-4 untuk setiap poin pernyataan.

\section{HASIL DAN PEMBAHASAN}

Uji Korelasi yang di lakukan dalam penelitian ini dilakukan untuk mengetahui adanya korelasi atau hubungan antara satu variabel dengan variabel yang lainnya. Hasil uji korelasi antar variabel menunjukkan nilai signifikansi di bawah 0,01 untuk masing masing variabel. Hal ini mengindikasikan bahwa terdapat hubungan erat antar variabel yang di gunakan dalam penelitian ini. Variabel Perencanaan, Koordinasi, 
Pengawasan, dan kepemimpinan masing masing memiliki hubungan yang sangat signifikan terhadap variabel kepuasan.

Berdasarkan hasil analisis bevariat dengan Product Moment, menunjukkan hubungan diantara variabel, baik variabel bebas (independen) maupun variabel terikat (dependent variable) menunjukan hubungan yang sangat tinggi dengan tingkat signifikanti satu (1\%) persen. Dengan hasil analisis tersebut dapat dinyatakan bahwa variabel independen (perencanaan, pengawasa, koordinasi dan kepemimpinan) berhubungan yang sangat tinggi dengan tingkat kepuasan masyarakat, tingkat signifikasi satu persen. Sebagaimana dalam analasis bevariat tersebut. Untuk lebih jelasnya dapat dilihat pada tabel 1 berikut ini.

Tabel 1

Statistik Deskriptif dan korelasi

\begin{tabular}{rrrrrrrrr}
\hline \multirow{2}{*}{ No } & \multirow{2}{*}{ Variabel } & \multirow{2}{*}{ Mean } & Stan. & \multicolumn{5}{c}{ Correlation } \\
\cline { 5 - 8 } & & & Dev & 1 & 2 & 3 & 4 & 5 \\
\hline 1 & Kepuasan & 68,5000 & 5,84600 & 1 & & & & \\
2 & Perencanaan & 37,7200 & 3,95079 &, $394^{* *}$ & 1 & & & \\
3 & Koordinasi & 36,5900 & 3.84791 &, $400^{* *}$ &, $785^{* *}$ & 1 & & \\
4 & Pengawasan & 35,9700 & 3.88296 &, $086^{* *}$ &, $683^{* *}$ &, $650^{* *}$ & 1 & \\
5 & Kepeminpinan & 67,6500 & 6.89947 &, $443^{* *}$ &, $490^{* *}$ &, $734^{* *}$ &, $572^{* *}$ & 1 \\
\hline
\end{tabular}

**. Correlation is significant at the 0.01 level (1-tailed).

Uji Regresi yang dilakukan dalam penelitian ini bertujuan untuk mengetahui pengaruh dari variabel independen terhadap variabel dependen baik secara bersama sama maupun secara bersama-sama atau secara parsial. Hasil uji regresi pada tabel 2 menunjukkan bahwa Perencanaan, Koordinasi, Pengawasan, dan kepemimpinan secara bersama sama dapat menjelaskan tingkat kepuasan stakeholder sebesar 49,5\%. Secara parsial, terdapat pengaruh positif signifikan antara perencanaan dengan kepuasan stakeholder dan terdapat pengaruh negatif signifikan anata pengawasan dengan kepuasan stakeholder, sedangkan koordinasi tidak mempengaruhi kepuasan stakeholder Dispendukcapil. 
Tabel 2

Hasil Analisis Regresi Berganda Variabel Kepuasan Stakeholder

\begin{tabular}{lcccc}
\hline $\begin{array}{l}\text { Variabel } \\
\text { Independen }\end{array}$ & $\begin{array}{l}\text { Koefisien } \\
\text { Regresi }\end{array}$ & Std. Error t & Sig. \\
& 29,633 & 3,785 & 7,829 & 0,000 \\
\hline (Constant) & 0,546 & 0,133 & 4,100 & $0,000^{*}$ \\
Perencanaan & $-0,016$ & 0,160 &,- 101 & 0,920 \\
Koordinasi & $-0,385$ & 0,115 & $-3,364$ & $0,001^{*}$ \\
Pengawasan & 0,059 & 0,072 & 0,820 & 0,414 \\
Kepeminpinan & 0,508 & & & \\
$\mathrm{R}^{2}$ & 0,495 & & & \\
Adjusted $\mathrm{R}^{2}$ & 38,580 & & & \\
F & & & & \\
\hline
\end{tabular}

*Signifikansi : $5 \%$

Adjusted R Square : 49,5\%

Perencanaan berpengaruh positif dan signifikan terhadap kepuasan masyarakat (stakeholder). Hasil ini sesuai dengan hipotesis pertama yang diajukan dalam penelitian ini, atau dengan kata lain hipotesis pertama diterima. Semakin baik perencanaan yang dimiliki oleh Disependukcapil, maka semakin baik atau semakin tinggi pula tingkat kepuasan masyarakat (stakeholder). Sesuai dengan perspektif teori stakeholder, perencanaan yang baik akan menghasilkan kinerja yang baik dan outocome yang baik pula berupa tingginya tingkat kepuasan stakeholder pada suatu organisasi (Berry dan Wechsler, 1995; Sautter dan Leisen, 1999).

Dispendukcapil dalam hirarki pemerintahan republik Indonesia merupakan bagian dari Kementerian Pendayagunaan Aparatur Negara dan Reformasi Birokrasi Republik Indonesia. Dalam praktiknya Kementerian Pendayagunaan Aparatur Negara dan Reformasi Birokrasi selalu memperbaiki perencanaan yang mereka buat. Peneltian ini juga sejalan dengan penelitian dari Kim dan Bopp di atas. (Kim, 2002) dan (Bopp, 2012). 
Hakekatnya pemerintah dalam menjalankan pelayanan memiliki tiga fungsi pokok dengan tidak melihat tingkatan atau strata, jenis, agama maupun etnis dalam masyarakat, yaitu publik services-function (fungsi pelayanan masyarakat), development function (fungsi pembangunan), dan protection function (fungsi perlindungan) yang kemudian akan melahirkan barang dan jasa yang dibutuhkan dalam Etika Adminitrasi Negara.

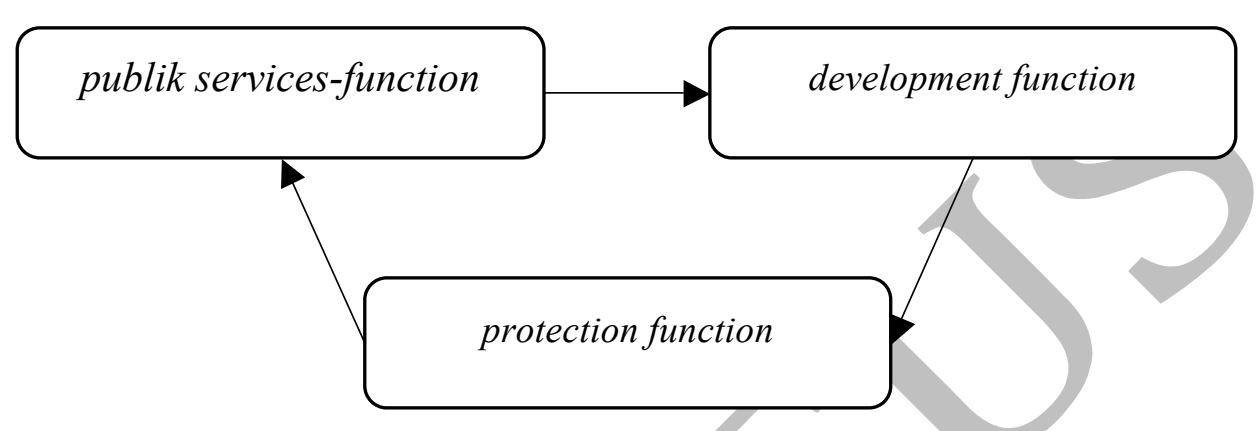

Diadaptasi dari: (Kemenpan, 2004) dan (Kumorotomo dan Margono, 1994).

Koordinasi tidak berpengaruh terhadap kepuasan stakeholder. Hasil ini tidak sesuai dengan hipotesis kedua penelitian sehingga hipotesis kedua dalam penelitian ini ditolak. Hal ini dapat terjadi dikarenakan buruknya koordinasi yang dilakukan oleh Dispendukcapil dengan stakeholdernya. Bisa saja Dispendukcapil tidak mengkoordinasikan kebijakan yang telah dibuat kepada stakeholdernya nya. Penyampaian kebijakan yang telah dibuat oleh kantor Dispendukcapil sangat penting dalam penyediaan pelayanan publik kepada stakeholder.

Hasil pengujian pengawasan membuktikan bahwa terdapat hubungan yang negatif siginifikan anatara pengawasan dan juga kepuasan stakeholder terhadap pelayanan publik yang dilakukan oleh dispendukcapil. Oleh karena itu, dapat disimpulkan bahwa hipotesis ketiga dalam penelitian ini ditolak. Dalam pengawasan terdapat dua sisi yang berbeda. Dalam pengawasan terdapat sisi gelap dimana pengawasan bersifat keras dan penilaian terhadap sesuatunya berdasarkan subjektifitas dari pengawas. Mungkin saja pengawasan yang dilakukan oleh dispendukcapil termasuk pengawasan yang keras ini sehingga dalam praktiknya faktor pengawasan tidak berpengaruh terhadap kepuasan skateholder. 
Kepemimpinan juga salah satu faktor yang tidak berpengaruh terhadap kepuasan. Sehingga dapat diambil kesimpulan bahwa hipotesis ke empat dalam penelitian ini tidak diterima. Dalam sebuah organisasi sosok pemimpin sangat mempengaruhi tujuan organisasi dalam mencapai goal congruencenya. Mungkin saja di kantor dispendukcapil ini pemimpin (kepala kantor) nya bukan dari bidang yang sama dengan bidang pelayanan dispendukcapil sehingga tidak bisa membawa organisasinya untuk mencapai goal congruence. Sebuah hal yang biasa di daerah kepala kantor/ kepala dinas dimutasi, akan tetapi mutasi tersebut tidak sesuai dengan kemampunan dari kepala kantor atau kepala dinas.

\section{KESIMPULAN}

Berdasarkan hasil uji korelasi yang dilakukan dalam penelitian ini mengindikasikan adanya hubungan yang erat antar variabel independen dangan variabel dependen. Hasil pengujian product moment (rxy) (reprosical corelation) menunjukkan hubungan yang sangat erat antara faktor Perencanaan, Koordinasi, Pengawasan dan Kepemimpinan transaksional dengan tingkat kepuasan masyarakat di kantor Dinas Kependukkan dan Pencatatan Sipil di Kabupaten Magetan dengan tingkat signifikansi satu (1) persen.

Bila dilihat dari hubungan sebab akhibat (recucent relationship), maka hubungan langsung kepada tngkat kepuasan masyarakat adalah variabel perencanaan, pengawasan dan Kepemimpinan. Sedang variabel koordinasi tidak menunjukkan pengaruh yang signifikan Sedang variabel pengawasan cenderung memiliki pengaruh negatif terhadap tingkat Kepuasan. Nilai adjusted R2 sebesar 0,508. Hal ini menunjukkan bahwa sebesar $51 \%$ variasi dari tingkat kepuasan masyarakat (stakeholder) terhadap kantor Dispendukcapil dapat diterangkan oleh variabel Perencanaan, Koordinasi, Pengawasan dan Kepemimpinan, sedangkan sisanya sebesar $49 \%$ diterangkan oleh variabel lain di luar model regresi pada penelitian ini.

Pengujian regresi secara parsial menunjukkan faktor Perencanaan berpengaruh secara positif terhadap tingkat kepuasan stakeholder, sedangkan variabel pengawasan berpengaruh secara negatif terhadap kepuasan. Kemudian faktor koordinasi dan kepemimpinan tidak berpengaruh terhadap tingkat kepuasan stakeholder. Hal ini dikarenakan kurangnya koordinasi antara kantor dispendukcapil dan juga stakeholder 
yang terlibat dan juga leader style yang berbeda dalam Dispendukcapil menyebabkan faktor kepemimpinan tidak berpengaruh terhadap kepuasan stakeholder.

\section{IMPLIKASI}

Penelitian ini memberikan implikasi terhadap teori dan praktik tatakelola kantor dispendukcapil. Hasil dari penelitian ini sejalan dengan teori stakeholder, yaitu terdapatnya hubungan dan pengaruh yang erat antara perencanaan yang baik, pengawasan yang teliti dan kepemimpinan yang mumpuni terhadap tingkat kepuasan yang dirasakan oleh para stakeholder. Penelitian ini juga mengungkap adanya inkonsistensi dan perbedaan hasil dari faktor koordinasi terhadap kepuasan stakeholder.

Penelitian selanjutnya diharapkan dapat menggunakan kantor lain selain kantor disependukcpil. Hal ini dimaksudkan untuk memperoleh gambaran yang jelas mengenai faktor yang mempengaruhi tingkat kepuasan stakeholder terhadap pengelolaan sebuah kantor milik pemerintah. Penelitian selanjutnya juga dapat dapat mempertimbangkan penambahan faktor lain yang tidak diteliti di dalam model ini seperti faktor transparansi atau akuntabilitas pengelolaan.

\section{SARAN}

Berdasarkan hasil temuan penelitian dan kajian teoritis ini disarakan ada beberapa hal, antara lain:

1. Untuk meningkatkan kepuasan masyarakat dalam pelayanannya, perlu adanya program yang terpadu dan komprehensif terhadap pelayanan yang membutuhkan hal-hal yang berkaitan dengan Disdukcapil Kabupaten Magetan.

2. Seyogyanya perlu pengawasan melekat a semua SKPD (Satuan Kerja Pemerintah Daerah) yang berdinas di Disdukcapil Magetan.

3. Berdasarkan hasil bevariat dan regresi ganda, perlu dipikirkan perencanaan yang komprehensif dan matang pada setiap program keDisdukcapil Kabapaten Magetan.

4. Perlu dibicarakan bersama di kalangan SKPD Disdukcapil dalam mengkoordinasi dan mengelola program yang sedang atau yang akan diluncurkan kepada 
Masyarakat. Hal ini agar tidak terjadi kesalah fahaman antara pimpinan denagn anggota SKPD di Disdukcapil.

5. Perlu dipikirkan jenis atau tipe kemimpinan yang sesuai dengan kondisi dan situasi di SKPD Disdukcapil, agar iklim atau suasana kekeluargaan yang telah dibangun di Disdukcapil bisa semakin erat dan semakin harmonis, sehingga setiap anggota SKPD merasa memilik dan senasib seperjuangan.

\section{DAFTAR PUSTAKA}

\section{Peraturan perundang-undangan:}

Kementerian Pendayagunaan Aparatur Negara dan Reformasi Birokrasi Republik Indonesia

\section{Buku Referensi:}

Allan, C., et al. (2013). "Climate Change and Water Security: Challenges for Adaptive Water Management." Current Opinion in Environmental Sustainability 5(6): 625-632.

Berry, F. S. dan B. Wechsler (1995). "State Agencies' Experience with Strategic Planning: Findings from a National Survey." Public administration review: 159-168.

Bopp, T. (2012). "Strategic Management and Job Satisfaction: Agency-Level Effects in the Federal Government."

Bramwell, B. (2011). "Governance, the State and Sustainable Tourism: A Political Economy Approach." Journal of Sustainable Tourism 19(4-5): 459-477.

Bryson, J. M. (2011). Strategic Planning for Public and Nonprofit Organizations: A Guide to Strengthening and Sustaining Organizational Achievement, John Wiley \& Sons.

Bucknall, J., et al. (2006). "Good Governance for Good Water Management." Environment Matters. Annual Review. World Bank, Washington DC (US): 2023.

Fandy, T. (1997). "Strategi Pemasaran." Yogyakarta: Penerbit Andi Offset.

Fandy, T. (2000). "Prinsip-Prinsip Total Quality Service." Yogyakarta: Andi Offset.

Freeman, R. (1984). "Srategic Management: A Stakeholder Approach (Marshall, Ma/Pitman)." 
Frieder, R. E., et al. (2015). "Attenuating the Negative Effects of Abusive Supervision: The Role of Proactive Voice Behavior and Resource Management Ability." The Leadership Quarterly 26(5): 821-837.

Fuller, J. B., et al. (1999). "The Effects of Psychological Empowerment on Transformational Leadership and Job Satisfaction." The Journal of Social Psychology 139(3): 389-391.

Gray, R., et al. (1997). "Struggling with the Praxis of Social Accounting: Stakeholders, Accountability, Audits and Procedures." Accounting, Auditing \& Accountability Journal 10(3): 325-364.

Harvey, P., et al. (2014). "Abusive Supervision and the Entitled Employee." The Leadership Quarterly 25(2): 204-217.

Hatipoglu, B., et al. (2016). "Barriers to Stakeholder Involvement in the Planning of Sustainable Tourism: The Case of the Thrace Region in Turkey." Journal of Cleaner Production 111: 306-317.

Kim, S. (2002). "Participative Management and Job Satisfaction: Lessons for Management Leadership." Public administration review 62(2): 231-241.

Kumorotomo, W. dan S. A. Margono (1994). Sistem Informasi Manajemen: Dalam Organisasi-Organisasi Publik, Gajah Mada University.

Lyu, Y., et al. (2016). "Abusive Supervision and Customer-Oriented Organizational Citizenship Behavior: The Roles of Hostile Attribution Bias and Work Engagement." International Journal of Hospitality Management 53: 69-80.

Mahmudi, S. (2005). "Manajemen Kinerja Sektor Publik." Akademi Manajemen Perusahaan YKPN, Yogyakarta.

Nasir, S. dan A. Masek (2015). "A Model of Supervision in Communicating Expectation Using Supervisory Styles and Students Learning Styles." Procedia-Social and Behavioral Sciences 204: 265-271.

Nishimura, T. dan T. Suzuki (2016). "Aspirations and Life Satisfaction in Japan: The Big Five Personality Makes Clear." Personality and Individual Differences 97: 300-305.

Roberts, R. W. (1992). "Determinants of Corporate Social Responsibility Disclosure: An Application of Stakeholder Theory." Accounting, Organizations and Society 17(6): 595-612.

Robson, J. dan I. Robson (1996). "From Shareholders to Stakeholders: Critical Issues for Tourism Marketers." Tourism management 17(7): 533-540.

Sautter, E. T. dan B. Leisen (1999). "Managing Stakeholders a Tourism Planning Model." Annals of tourism research 26(2): 312-328.

Sekaran, U. dan R. Bougie (2010). Research Method for Business, a Skill Building Approach. John Wiley \& Sons Inc, Singapore.

Song, H., et al. (2012). "Tourism Value Chain Governance: Review and Prospects." Journal of Travel Research: 0047287512457264. 
Ugboro, I. O. dan K. Obeng (2000). "Top Management Leadership, Employee Empowerment, Job Satisfaction, and Customer Satisfaction in Tqm Organizations: An Empirical Study." Journal of Quality management 5(2): 247-272.

Valente, F., et al. (2015). "Leadership and Governance in Regional Tourism." Journal of Destination Marketing \& Management 4(2): 127-136.

Zsolnai, L. (2006). "Extended Stakeholder Theory." Society and Business Review 1(1): $37-44$.

Zaini Rohmad, dkk. 2009. Model Kemitraan Antar Stakeholder di Malang Raya, Laporan Penelitian, Unpublished. LPPM UNS Surakarta.

Zaini Rohmad, dkk. 2015. Resolusi Konflik Pengelolaan Air Di Wilayah Pariwisata Kabupaten Karanganyar. Laporan Penelitian, Unpublished. LPPM UNS Surakarta

Zaini Rohmad, 2015. Indeks Kepuasan Masyarakat dalam Pelayanan Publik di Kabupaten Magetan. Laporan Penelitian, Unpublished. LPPM UNS Surakarta 